investigation and discussion that we finally arrive at the truth.

No great discovery or improvement has ever been accepted unquestioned by the medical profession. It was twenty-five years after Harvey demonstrated the circulation of the blood before it was accepted by the profession at large, and it is recorded in history as a fact that no member of the profession who was then over 40 years old ever gave in his adherence to the doctrine. The same is true in regard to Jenner's discovery of vaccination.

In I 809, when Ephraim McDowell, of Kentucky, demonstrated the practicability of ovariotomy, he was assailed by every prominent surgeon then living, and the operation was compelled to fight for a full half century, and finally established itself as a legitimate operation, but over the dead body of every prominent surgeon who was practicing at the time it was first proposed.

Dr. H. C. ERnst, Massachusetts, agreed with Drs. Welch and Fitz, and then went on to describe the advantages and disadvantages of the different stain. ing processes which had been recommended, and then called attention to the fact that in performing these investigations nothing less than an immersion lens, with some sort or sub-stsge illuminating apparatus, would give reliable results.

Dr. William Pepper, Philadelphia, had observed similar cases to those described by Dr. Janeway, but his observations had led him to a directly opposite conclusion. He did not believe in the contagiousness of tuberculosis. In the experiments which Dr. Formad had performed, great care was taken to place the animals under the best hygienic surroundings; some were sent to the country, and all were given plenty of fresh air. He thought that there were many other ways of explaining the connection of the bacillus and tuberculosis than the assumption that the bacillus held a casual relation to tuberculosis.

Dr. Traill Green, of Easton, Pa., did not believe that tuberculosis was a contagious disease, and referred to the fact that working in grindstone factories would soon induce tuberculosis in perfectly healthy individuals.

In closing the discussion, Dr. Formad said that he was highly gratified, and felt thankful to the section that so much time had been allowed to a debate which had been so interesting and instructive to him. He did not see fit to comment upon the remarks of the many prominent gentlemen who participated in the discussion; yet he felt somewhat disappointed, for he had hoped that more stress would have been laid upon facts than on views, and that some accounts of active personal work would have been elicited. He thought that Koch had not made out his case fully, and that it brought others into misconception to rely upon his statements in regard to the etiological relations of his bacillus, and that it would be well to await further developments in a question of such grave importance, instead of jumping with Koch to hasty conclusions. To the merits of Koch's discovery in regard to the diagnostic value of his bacilJus in tuberculosis, 1)r. Formad did full justice.

\section{A CASE OF CALCULUS OF THE URETHRA.}

\author{
BY I.. H. DUNNING, M.D., \\ OF SOUTH BEND, IND.
}

J. S., a farmer, consulted me on August $4, \mathrm{x} 884$, for the removal of a stone from the urethra. $\mathrm{He}$ stated that he was 62 years old, and that for a number of years he had suffered intensely at times in consequence of gravel; that he had at times passed small gravel, but had no suspicion of the presence of a stone in the bladder. Some time in January, I 884 , a stone, which he thought to be as large as a hickory nut, had entered the urethra from the bladder, and passed down and lodged in the penis, just behind the glans. At this point it remained and gradually increased in size until he presented himself for treatment.

The penis then measured seven and one-half inches at its point of greatest circumference, which was three and one-half inches posterior to the meatus. The whole penis was much enlarged and of a dark livid hue. Several openings, readily admitting the passage of a small probe, were found leading from without inwards into the urethra posterior to the stone. The external orifices of these false passages were slightly excavated, and presented an almost gangrenous appearance, and from them the urine was oozing constantly. The patient stated that two or three weeks previous to this time he had noticed that but little urine escaped from the orifice of the urethra, and thinking that the stone had plugged the passage, he one day made a hole with a gimlet through the center of the stone parallel with the urethra; but he found that even then the urine could pass through the orifice only drop by drop. He tried to remove the whole of the calculus, but failed.

On August 7 , assisted by Drs. Hitchcock and Gist, of this city, the stone was quickly removed. An incision one and one-half inches long was made in the urethra, from the orifice backward. The stone was crushed and removed in fragments. A pouch was found, in which the stone had rested, of sufficient size to hold fully one ounce of water. The weight of the stone was afterward found to be 300 grains. The walls of this pouch were dense and hard. An unsuccessful attempt was made to pass a small bougie from the bottom of this pouch into the urethra. There was doubtless a communication between the pouch and the urethra, but it was so small or so well concealed that it could not be found. With a view of making a free passage for the urine, I cut down upon and into the urethra just in front of the scrotum, and passed a grooved director forward along the urethra until the pouch was reached; then along the groove of the director a sharp-pointed probe was passed through the posterior wall of the pouch, the end of the director being made to follow it, after which the opening was enlarged with a probe-pointed bistoury. Having no suitable silver tube with me, a portion of a soft rubber catheter was passed through the pouch into the urethra, beyond the posterior extremity of the incision, and made fast. An effort was made to pass a small bougie into the bladder, but it was unsuccessful, as it was impossible to carry the bougie 
beyond the bulbo-membranous portion of the urethra. Concluding that all had been done for the patient that could be done at this time, the wounds were closed by interrupted sutures, properly dressed, and patient put to bed.

He rallied well, and everything went favorably until recovery took place, three weeks after the operation. At the end of that time the wounds were almost healed, and the patient was around the house. On August I I, four days after the operation, the patient passed voluntarily a small stream of urine, and again on the next day. After that date he had almost complete control of the urine, there being only a slight amount of incontinence after the first week.

The incision nearest the bladder healed partly by first intention, and the remainder rapidly filled by granulation, so that at the end of six weeks it was closed. The tube was removed every day, and cleansed and replaced. At the end of the first week its use was discontinued, though a soft bougie was introduced every few days.

The patient gradually regained his health, so that during the past winter he has been in a better condition, physically, than for a number of years. $\mathrm{He}$ suffers no pain and discharges a small-sized stream of urine without much effort. He persistenlty refuses to allow anyone to explore the urethra or bladder, being content to let well enough alone, and is happy in having been so fortunate as to escape from so serious a dilemma.

\section{MEDICAL PROGRESS.}

\section{ANATOMY AND PHYSIOLOGY.}

ON the Sources and the Excretion of CarBONiC ACid in THE Liver.-Dr. J. J. Charles, in the Journal of Anatomy and Physiology gives a very comprehensive view of this subject. He assumes that a molecule of albumen might be supposed to combine with 50 molecules of water and yield 8 molecules of urea, 7 of glycogen, 5 of carbonic acid, 7 of oxygen, and $I$ of sulphuric acid. The oxygen might enter into combination with reduced hæmoglobın or other substances. Carbonic acid has been obtained in the laboratory from albumen. We can readily believe in the albumen of the tissues, particularly the muscnlar and the nervous, undergoing these chemical changes during its metabolism, and so account for the carbonic acid present in all the tissues, and for the urea found in some of them. There can be no doubt that the destruction of albuminous material is most active at the liver, for this organ, as we know, contains about a fourth of the total blood of the body; besides there is to be found in the liver a great number of nitrogenous substances intermediate between albumen and urea, such as leucin, tyrosin, xaultrin, hypoxaultrin, uric acid, etc. According to most authorities, also, there is more urea to be met with in this organ than in any other in the body. The urea certainly cannot be derived from the blood by a mere process of filtration into the liver; for the nervous and muscular tissues, which do not directly produce urea, contain little or none of it.

Dr. Zuelzer advances the hypothesis that the higher albumen derivative hæmoglobin, is broken up in the liver into a number of simpler bodies, viz: taurocholic acid, glycocholic acid, bilirubin, urea, cholesterin, carbonic acid. He calculates that 13.332 grammes of hæmoglobin, with the necessary water and oxygen, yield 2.486 grammes of carbonic acid. A further decomposition of a smaller proportion of hæmoglobin with the formation of glycogen is probable. As $13.33^{2}$ grammes of hæmoglobin yield 0.572 gramme of carbonic acid and 12.96 grammes of glycogen.

Owing to the destruction of red blood corpuscles which are constantly occurring in the spleen, a considerable quantity of hæmoglobin in solution is as constancy being carried to the liver. A calculation has been made which indicates that the duration of the life of a red corpuscle is, at most, about thirty days. There can be little doubt that, as Heidenhain and others suppose, albumen in some form is decomposed in the cells of the liver, and biliary and pigments form in the same cells as the glycogen. It is true that these two processes in the liver, resulting in the formation of glycogen and bile, though both are attended by a corresponding production of carbonic acid, differ markedly in that their periods of intenrity do not synchronise; and, further, in that whilst the biliary secretion continues during starvation, the formation of glycogen ceases.

The amount of carbonic acid excreted by the liver is very large. In the bile collected directly as it flowed from the liver of a dog, Dr. Charles found a total of 57 volumes per cent. of carbonic acid. That this proportion of carbonic acid is very gréat can readily be understood, when it is stated that there are only 34 vols. per cent. of the gas present in the arterial blood of the dog, and 46 vol. per cent. in the venous blood of the same animal. From the bile of the rabbit the only herbivorous animai in which freshly secreted bile has up to the present been examined, he obtained a total of 109 vols. per cent. of carbonic acid, free and combined, a larger proportion than has yet been discovered in the fluids of any animal, but only slight traces of oxygen and nitrogen.

With regard to the possible source of the large amount of carbonic acid excreted at the liver, two views suggest themselves:

(a.) That the carbonic acid is produced in the different tissues and organs of the body, the liver included, and some of it then passes out by simple diffusion or solution from the postal and hepatic capillaries into the bile (as may occur at the pleura in lymph undation), the hepatic cells not being specially concerned in the process: and

(b.) That in addition to this general formation of carbonic acid in the body, there is a special production of the gas at the liver, owing to the decomposition in the hepatic cells of such bodies as albumen and hæmoglobin. Of the carbonic acid thus generated in the liver, part will enter the blood and a larger quantity the bile, particularly if this fluid is alkaline. The amount of combined carbonic acid 